\section{Community Work: Theories, Experiences \& Challenges}

Goel, K., Pulla, V. and Francis, A. P. (Eds.), 2014. Bangalore: Niruta Publications, 262 pages, A\$29.95, Rs. 350/-

Jennifer Woods ${ }^{\dagger}$

"Community development has been identified as a core social work approach or method to work with communities who are disenfranchised, marginalised and faced with broad social issues resulting from unjust policies and planning at global, national, state and local level." (Goel et al, 2014, p. 5)

This text re-explores community development within a contemporary social work framework for service provision in a changing world. With increased technology that has changed the nature of community to encompass online aspects and a changing political and economic climate, community development must adapt to this ever-changing environment. The introductory chapter outlines the content of the fifteen chapters that this book offers to its reader, which include: community development and microfinance, community development for immigrant communities, safety-net groups for community building, community development and organisational change, the impact of globalisation on communities, culturally competent community development work, rural community development, African diasporic community development, health promotion and community enhancement, community development and disaster management, arts and community development and mental health in community development.

Kalpana Goel, in the first chapter of this book, offers new definitions for contemporary

${ }^{\dagger}$ PhD candidate at Charles Sturt University, WaggaWagga, Australia Email: jwoods@csu.edu.au, jmiegel2@bigpond.com

(C)2014 Woods. This is an Open Access article distributed under the terms of the Creative Commons Attribution License (http://creativecommons.org/licenses/by/2.0), which permits unrestricted use, distribution, and reproduction in any medium, provided the original work is properly cited. communities and discusses the improved awareness of the functions of a community. Here, Goel identifies social work as ideally placed to address issues of social justice, marginalisation and human suffering within a community development framework but stresses that community development must fit into the community context in which it is being applied, taking account of contemporary heterogeneous society. Goel further comments on the principles and strategies of community development and their application within social work and completes her chapter with discussion on education for social workers in community development frameworks.

Chapter 2 by Gopalkhrishnan explores the concept of globalisation and the impact it has has on communities and individuals. He further goes on to discuss the role that social workers can play, utilising community development frameworks, to address the issues and problems that globalisation has created.

The third chapter by Riggs and Pulla provides an in-depth discussion regarding the ability of visual and theatre-based arts to enhance community development and create a healing modality for trauma, leading to increased resilience at the individual and community levels.

Continuing, Penman in Chapter 4 uncovers the potential for community development frameworks to enhance community capacities via the delivery of health education at the grassroots level. The grassroots programmes evaluated in this chapter have been delivered utilising a spiritual setting and analysed on the basis of the impact they have on the health of the participants. Enhancing the health capacity of a community inevitably has a positive correlation with resilience building and thus provides a means to community development.

Percey and Orpin consider, in their chapter, the involvement of community development 
practices in rural communities. Of particular interest is the discussion regarding the static nature of the rural community with its isolation and readily identifiable boundaries, which also allow for easy recognition of community identity.

Safety-net groups are identified as community support groups, which facilitate collective work towards community development. This is the concept discussed in the chapter by Francis and Zuchowski which links community development with group work - two well-defined social work practice interventions. Safety-net groups allow for self-determined and empowered community development that is in the best interest of the community itself.

Disaster management, a growing field for social work for which community development is an appropriate model in a global situation of increased impact and intensity of disasters with less state-provided intervention. The application of strengths-based theories for social work with a community development framework, which enhance resilience, is the focus for this chapter by Bhadra and Pulla.

In their Chapter 8, Velander and Schineanu explore community development, which is culturally competent, and with particular regard to Australian indigenous communities. The authors discuss what constitutes culturally competent community development work and endorse the use of strengths-based practice theories, which endeavour to promote wise practice, the best choice of practice frameworks for community work with Australian indigenous communities in remote areas.

The next chapter by Nikku investigates the means to educating the South Asian social work profession with regard to community development work that attempts to alleviate the issues of an increasingly globalised world coupled with internal conflict and decreased governance.

A chapter which considers the application of community development frameworks for social work with regard to mental health promotion is presented by Francis, Pulla and Goel. The authors endorse the use of strengths-based theories to address mental health issues by way of increasing resilience and promoting community spirit.

Microfinance as a means to supporting people with mental illness issues in Uganda is the next topic for discussion in this book. This chapter looks at the way in which microfinance can bridge the gap in coping with mental health problems that has been caused by families becoming nucleated or isolated in urban areas. The role of microfinance is seen as providing social support for people as a means to increasing their social capital and building the community.

Goel in Chapter 12 explores the role of community-based organisations in humanitarian resettlement programmes. Goel goes on to conclude that community development programmes and principles are the "backbone (p. 196)" of ethical and professional service provision for refugees and humanitarian entrants.

Similarly, wa Mungai in Chapter 13 looks at Ubuntu approaches to community development with immigrant communities referring to the view of the African communities as self-determining rather than accepting of the marginalised position offered by the dominant, hegemonic culture and looks at the role of extended family to African cultures and the issues faced by diasporic African communities in Australia.

Finally, Mamidi and Chada look at the cooperative organisation of the street vendors in India, who form a major economic component and are creating significant civil issues within their community. Community development can pave the way forward to safe organisation of what is an historic component of urban life for India.

The concluding chapter wraps up the concept of community development for the future of social work in an era of downsized governments and increased need with uncertainty a key feature of contemporary 
society. Here, Francis and Pulla once again reiterate the appropriate pairing of strengthsbased practice theories with community development frameworks for ethical social work service delivery that aims to alleviate the issues created in an uncertain world.

Clearly, with significant chapters that relate to both the Australian and wider, global context, this text provides a wealth of information for social work in a new environment brought about by globalisation, climate change and neoliberal political ideology that is witnessing the increased widening of the gap between rich and poor, increased numbers of people living in poverty and people facing increased risk of impact from disasters instigated by changes in climate. A comprehensive text, priced competitively, this text has the potential to add great benefit to the available literature on community development in the Australian context. The book also makes for a good textbook in South Asia and South East Asia. With clear and concise chapters written with respect to the ethical guidelines for Australian social work practice, this text fills the gap with a fresh lens that promotes community development in contemporary context. 